\section{Permanent Impairment of Renal Function after Methicillin Nephropathy}

\author{
H. ERENLUND JENSEN, A. B. HALVEG, \\ K. I. SAUNAMÄKI
}

British Medical fournal, 1971, 4, 406

A favourable prognosis has usually been given in cases of nephropathy due to methicillin, but until now there has been no report of the findings in a repeat renal biopsy. We report a case of methicillin nephropathy in which renal biopsy and investigations two years later showed evidence of residual renal damage.

\section{Case Report}

A 45-year-old man was admitted to hospital in a coma due to aprobarbital poisoning. He had signs of aspiration pneumonia, and culture of tracheal aspirate produced Staphylococcus aureus. Pyrexia responded to Fucidin $0.5 \mathrm{~g}$ six hourly by mouth and methicillin $1 \mathrm{~g}$ four hourly parenterally. After 15 days of treatment the patient's temperature rose over four days to $104^{\circ} \mathrm{F}\left(40^{\circ} \mathrm{C}\right)$, and this was accompanied by oliguria, proteinuria, and macroscopic hematuria. Blood eosinophils increased to $1,280 / \mathrm{mm}^{3}$ and serum creatinine to $67 \mathrm{mg} / 1$. Concomitantly creatinine clearance decreased to $16 \mathrm{ml} / \mathrm{min}$. There was no skin rash. Infusion urography and ${ }^{131}$ I-hippuran renography showed equal bilateral decrease in renal function with no signs of obstruction of the urinary tract. Methicillin was discontinued. The temperature fell abruptly, the eosinophilia and proteinuria disappeared, and the serum creatinine decreased to $18 \mathrm{mg} / \mathrm{l}$. after four weeks.

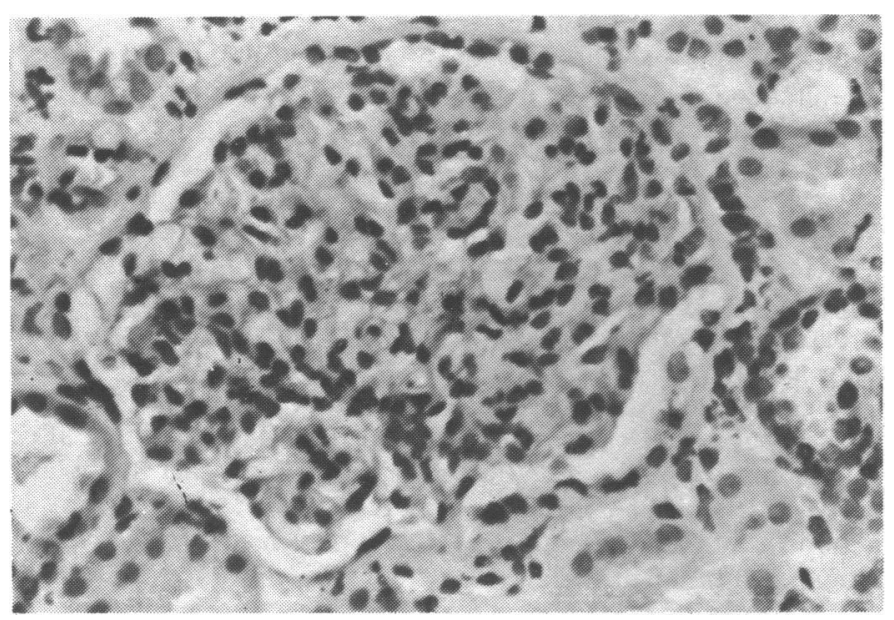

FIG. 1-Glomerulus with thickening of the basement membrane and ad hesions between the tuft and capsule (x 175).

Percutaneous renal biopsy was performed one month after stopping treatment with methicillin. Most of the 14 glomeruli in a representative sample appeared normal, but in some the tuft was enlarged with slight increase in cellularity, thickening of the basement membrane, and a few adhesions to the capsule. No accumulation of leucocytes, cellular proliferation of the capsule, or periglomerular fibrosis was seen (Fig. 1). The histological picture was

Departments of Nephrology, Pathology and Medicine, Glostrup Hospital, Denmark

H. ERENLUND JENSEN, M.B., Senior Registrar

A. B. HALVEG, M.B., Pathologist

A. B. HALVEG, M.B., Pathologist
K. I. SAUNAMAKI, M.B., Cardiology Registrar completely dominated by interstitial and tubular changes. The interstitial tissue showed oedema and large irregular peritubular infiltrations consisting mainly of lymphocytes but also some plasma cells and eosinophils granulocytes. The tubular damage varied from epithelial degeneration to necrosis with desquamated epithelium in the lumen but only a few casts. No changes were found in the vessels (Fig. 2). Six months later the urine was normal

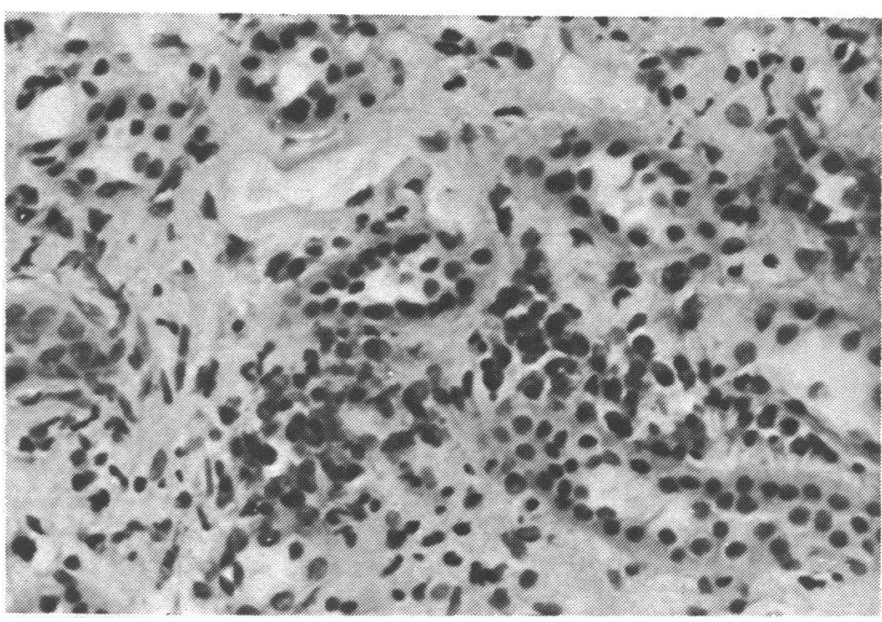

FIG. 2-Tubular damage, interstitial oedema, and infiltration with lymphocytes, plasma cells, and eosinophil granulocytes (x 175).

on microscopical examination, there was no proteinuria, and the serum creatinine was $15-16 \mathrm{mg} / 1$.

Two years later the ${ }^{51} \mathrm{Cr}$-EDTA clearance was $56 \mathrm{ml} / \mathrm{min} / 1.73$ $\mathrm{m}^{2}$ body surface, serum creatinine was $15 \mathrm{mg} / \mathrm{l}$., and blood urea nitrogen $0.44 \mathrm{~g} / 1$. There was no proteinuria nor glycosuria, and microscopical examination of the urine was normal. A representative biopsy specimen of renal cortex and medulla contained 12 glomeruli whose appearance was similar to those in the first biopsy-most were normal but in a few there was a slight increase in cellularity and thickening of the basement membrane; adhesions were also present. The entire biopsy showed only two hyaline glomeruli. The extensive interstitial cellular infiltrations had disappeared. A few atrophied tubules were seen at the hyaline glomeruli, but otherwise the tubules and collecting ducts were normal. As in the first biopsy, the vessels were normal.

\section{Comment}

The histological appearance of the interstitial tissue, the tubules, and the blood vessels previously reported (Baldwin et al., 1968; Brauninger and Remington, 1968; Simenhoff et al., 1968) are comparable to those in our case, but glomerular damage or residual impairment of renal function was not observed. In a further case (London, 1967) electron microscopic examination showed mild oedema of glomerular epithelial and mesangial cells with slight focal thickening and mottling of the basement membrane, particularly on its endothelial aspect.

The persistent glomerular changes and impaired renal function in our case seems to be explained by the methicillin nephropathy. We therefore suggest that methicillin may cause permanent renal damage.

Requests for reprints should be addressed to $H$. Erenlund Jensen, M.B., Medical Department B., Glostrup Hospital, 2600 Glostrup, Denmark.

\section{References}

Baldwin, D. S., Levine, B. B., McCluskey, R. T., and Gallo, G. R. (1968) New England fournal of Medicine, 279, 1245.

Brauninger G. E and Remington, J. S. (1968). Fournal of the American Medical Association, 203, 103

London, R. D. (1967). Fournal of Pediatrics, 70, 285.

London, R. D. (1967), W. R., and Dammin, G. J. (1968). American fournal of Medicine, 44, 618 . 